\title{
Management of a traumatic aortoesophageal fistula in a patient with a right-sided aortic arch
}

\author{
Daniel Vallböhmer, MD, Arnulf H. Hölscher, MD, PhD, Jan Brunkwall, MD, PhD, and Michael Gawenda, MD, PhD, \\ Cologne, Germany
}

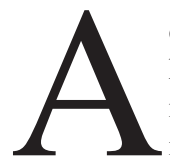

ortoesophageal fistulas are critical conditions with a high rate of morbidity and mortality. We present the management of a patient with a right-sided aortic arch in whom a traumatic aortoesophageal fistula developed after a car accident.

\section{Clinical Summary}

A 23-year-old woman was involved in a high-speed car accident and transferred to an outside hospital. Injuries at admission included fractures of the left pelvic ring, right humerus, multiple ribs, and lumbar vertebra. In addition, lung contusions and various skin lesions were present. Acute surgical therapy consisted of the stabilization of the pelvic fracture by external fixation and an intramedullary nailing of the humeral fracture.

Three weeks after an uneventful postoperative course, an acute hematemesis developed in the patient. Upper endoscopy failed to detect the localization of the gastrointestinal bleeding because of the persistence of the severe hematemesis. A laparotomy with gastrostomy was performed, revealing massive esophageal bleeding. A Linton-Nachlas balloon tube was placed, which stopped the bleeding.

The patient was transferred to an outside cardiothoracic department for surgical treatment of the suspected aortic arch dissection with traumatic aortoesophageal fistula. A sternotomy showed an unexpected right-sided aortic arch obscuring the region of interest. The fistula, $25 \mathrm{~cm}$ distal from the incisors, was identified through a right thoracotomy. Both the esophagus and the aorta were oversewn, which stopped the bleeding so the balloon tube could be removed. The patient was transferred back to the primary hospital, where another episode of acute hematemesis occurred 11 days after the closure of the fistula. A Sengstaken-Blakemore tube was inserted, which temporarily stopped the bleeding so the patient could be transferred to our department. Thoracic and abdominal computed tomograms could not localize the bleeding site. Controlled release of the tube under endoscopic visualization resulted

From the Department of Visceral and Vascular Surgery, University of Cologne, Cologne, Germany.

Received for publication June 26, 2007; accepted for publication July 19, 2007.

Address for reprints: Michael Gawenda, $\mathrm{MD}, \mathrm{PhD}$, Department of Visceral and Vascular Surgery, Division of Vascular Surgery, University of Cologne, Kerpenerstraße 62, 50937 Cologne (E-mail: michael.gawenda@ uk-koeln.de).

J Thorac Cardiovasc Surg 2007;134:1375-6

$0022-5223 / \$ 32.00$

Copyright () 2007 by The American Association for Thoracic Surgery doi:10.1016/j.jtcvs.2007.07.039 in massive esophageal bleeding. We suspected that a relapse of the aortoesophageal fistula was causing the recurrent gastrointestinal bleeding. An endovascular stent-graft (Talent Thoracic Endoprosthesis, $22 \times 22 \times 116 \mathrm{~mm}$; Medtronic AVE, Santa Rosa, Calif) was placed distal to the left common carotid artery through a right-sided transverse arteriotomy of the common femoral artery (Figure 1). Because of a type II endoleak, the left subclavian artery was interventionally coiled (Figure 2).

The patient was in stable cardiopulmonary condition postoperatively. Extubation was possible 11 days after stent-grafting, and the patient was transferred to a peripheral ward. Follow-ups with endoscopy and computed tomography demonstrated a local esophageal necrosis in the region of the former fistula, which was treated conservatively. The patient was discharged from the hospital after 67 days on a full oral diet.

Thirteen months later, the patient was urgently admitted to the regional hospital because of recurrent upper gastrointestinal bleeding. A laparotomy with gastrostomy was performed that revealed another massive esophageal bleeding. The bleeding was stopped by a Sengstaken-Blakemore tube, and the patient was transferred to our department. A relapse of the aortoesophageal fistula was described, and under circulatory arrest the stent-graft was removed and a resection of the aortic segment adherent to the fistula with an interposition aortic allograft was performed. In addition, a subtotal esophagectomy with cervical esophagostomy and placement of a jejunal feeding tube were performed. Postoperatively, anastomotic leakages of the homograft occurred and were covered by a stentgraft (Gore TAG Thoracic Endoprosthesis, $26 \times 100 \mathrm{~mm}$; WL Gore \& Associates, Flagstaff, Ariz).

The postoperative course was uneventful, and the patient was discharged with enteral feeding via the jejunal tube. Successful reconstruction of the gastrointestinal tract continuity was performed with colonic interposition 17 months later.

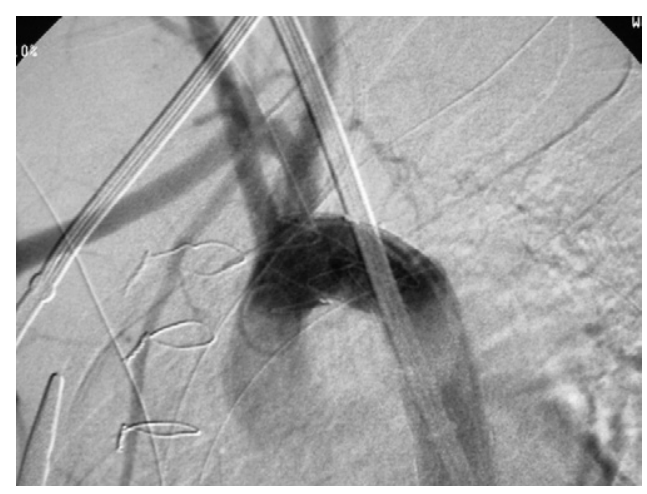

Figure 1. Intraoperative angiogram showing the endovascular stent-graft in the aortic arch and descending aorta. 


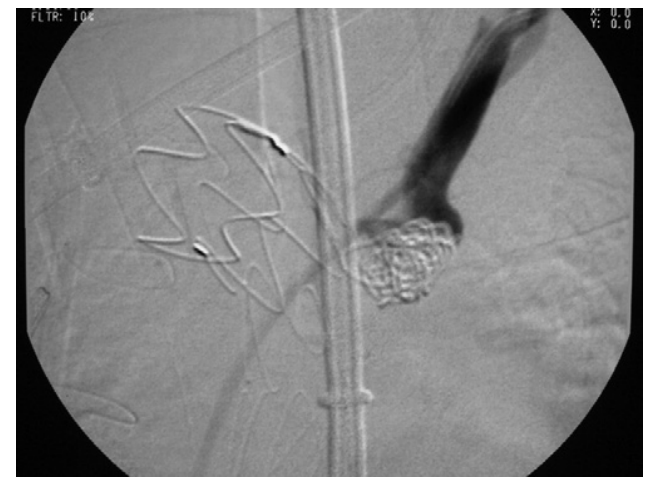

Figure 2. Angiogram showing the coiling of the left subclavian artery.

\section{Discussion}

The successful management of an aortoesophageal fistula remains a challenge. ${ }^{1-4}$ Moreover, therapeutic procedures are even more complicated in patients with a right-sided aortic arch. To date, 3 cases of an aortoesophageal fistula have been described in patients with a right-sided aortic arch, 2 of whom died as the result of a massive hematemesis. ${ }^{1-3}$ In addition to open surgery, endovascular approaches with stent-grafts to treat aortoesophageal fistulas have been described. ${ }^{4,5}$ Although the presented cases thus far underwent open surgery, our patient underwent an endovascular procedure by introducing a stent-graft in the aortic arch after an unsuccessful suture. To our knowledge, this is the first successful endovascular reconstruction of an aortoesophageal fistula in a patient with a right-sided aortic arch. However, the long-term outcome of endovascular therapy remains to be determined, because a recurrent aortoesophageal fistula developed in our patient, necessitating open surgery.

\section{References}

1. Edwards BS, Edwards WD, Connolly DC, Edwards JE. Arterial esophageal fistulae developing in patients with anomalies of the aortic arch system. Chest. 1984;86:732-5.

2. Matsuno $\mathrm{O}$, Matsumoto $\mathrm{T}$, Tsuda T. Aortic aneurysm involving a right-sided arch complicating aortobronchopulmonary and aortoesophageal fistula. Intern Med. 2001;40:722-5.

3. Rodriguez E, Park P, Cowan S, Weinstein M, Kaulback K, Friedberg J, et al. Complicated Management of a traumatic aortoesophageal fistula in a patient with a right sided aortic arch. J Trauma. 2004;56:691-3.

4. Leobon B, Roux D, Mugniot A, Rousseau H, Cerene A, Glock Y, et al. Endovascular treatment of thoracic aortic fistulas. Ann Thorac Surg. 2002; 74:247-9

5. Flores J, Shiiya N, Kunihara T, Yoshimoto K, Yasuda K. Aortoesophageal fistula: alternatives of treatment case report and literature review. Ann Thorac Cardiovasc Surg. 2004;10:241-6.

\title{
Four thymus-related syndromes in a case of invasive thymoma
}

\author{
Marco Lucchi, MD, ${ }^{\text {a }}$ Andrea Viti, MD, ${ }^{a}$ Roberta Ricciardi, MD, ${ }^{\mathrm{b}}$ Luigi Murri, MD, ${ }^{\mathrm{b}}$ and Alfredo Mussi, MD, ${ }^{\mathrm{a}}$ Pisa, Italy
}

T hymoma is an epithelial tumor that is frequently associated with autoimmune phenomena and paraneoplastic syndromes. The most frequent are neuromuscular ${ }^{1}$ and hematologic ${ }^{2}$ disorders; however, neurologic, ${ }^{3}$ dermatologic, ${ }^{4}$ ophthalmologic, and other disorders are reported. ${ }^{5}$ The surgical resection of the tumor and associated adjuvant therapies often result in an improvement or complete remission of the symptoms. On the other hand, a thymus-related syndrome sometimes develops months or years after the treatment of the thymoma. ${ }^{1}$ Moreover, the recurrence of thymoma may be accom-

\footnotetext{
From the Division of Thoracic Surgery, Department of Cardiac and Thoracic Surgery, ${ }^{\mathrm{a}}$ and Division of Neurology, ${ }^{\mathrm{b}}$ University of Pisa, Pisa, Italy.

Received for publication May 3, 2007; accepted for publication July 9, 2007.

Address for reprints: Marco Lucchi, MD, Division of Thoracic Surgery, University of Pisa, Via Paradisa 2, 56124 Pisa, Italy (E-mail: m.lucchi@med.unipi.it).

J Thorac Cardiovasc Surg 2007;134:1376-8

$0022-5223 / \$ 32.00$

Copyright $\odot 2007$ by The American Association for Thoracic Surgery doi:10.1016/j.jtcvs.2007.07.040
}

panied by recurrence of the originally associated paraneoplastic syndrome, even after many years.

The association of 2 or more paraneoplastic syndromes is rare in any case. We report a unique case of invasive thymoma and 4 thymus-related syndromes occurring in the preoperative setting.

\section{Clinical Summary}

A 43-year-old man with recurrent fever and limb petechiae was admitted to the internal medicine division of our hospital. Serum platelet count was $16 \times 10^{3} / \mu \mathrm{L}$, red cell count was $2.9 \times 10^{6} / \mu \mathrm{L}$, and hemoglobin concentration was $8.2 \mathrm{~g} / \mathrm{dL}$. The diagnosis of pure red cell aplasia and idiopathic thrombocytopenic purpura was made.

The marrow biopsy showed 1) a well-represented granuloblastic group with hyperplastic phenomenon, without morphologic anomalies; 2) a low presentation of red cells with some erythroblastic cells, and 3) anomalies in the distribution of lymphoid cells.

The patient also presented with a rheumatologic disease characterized by intense pain localized at the fingers and arms, which was treated with nonsteroidal anti- inflammatory drugs. The anemia and thrombocytopenia were treated with transfusions.

A standard chest $\mathrm{x}$-ray evidenced the presence of a voluminous mass of the anterior and superior mediastinum prominent on the 